\title{
HUBUNGAN FAKTOR PENYEBAB KECELAKAAN KERJA DENGAN KEJADIAN TERSAYAT PADA PEMBERSIH BAWANG DI PASAR SEGIRI DAN PASAR KEDONDONG SAMARINDA
}

\author{
Suwignyo $^{1}$, Dhea Fara Dhina ${ }^{2}$, Sinta Tri Rahayu ${ }^{3}$ \\ suwignyo@uwgm.ac.id ${ }^{1}$, fddhea@gmail.com ${ }^{2}$, shint_rahayu@yahoo.co.id ${ }^{3}$ \\ Universitas Widya Gama Mahakam, Samarinda
}

\begin{abstract}
ABSTRAK
Kecelakaan kerja adalah kejadian yang tidak diharapkan dan terjadi saat melakukan pekerjaan. Kecelakaan dapat timbul dari beberapa faktor yaitu faktor manusia, faktor lingkungan dan faktor peralatan. Penelitian ini bertujuan untuk mengetahui hubungan faktor penyebab kecelakaan kerja dengan kejadian tersayat pada pembersih bawang di Pasar Segiri dan Pasar Kedondong Samarinda. Jenis penelitian ini adalah explanatory research dan menggunakan rancangan cross-sectional dengan total sampel sebanyak 31 responden. Variabel yang diamati adalah alat yang digunakan, pencahayaan, masa kerja, usia dan penggunaan APD. Hasil analisis dengan menggunakan uji chi-square menunjukkan ada hubungan alat yang digunakan $(p=0,006)$, pencahayaan $(0,038)$, masa kerja $(p=0,013)$, usia $(0,045)$ dan penggunaan APD $(p=0,042)$ dengan kejadian tersayat pada pembersih bawang. Faktor penyebab kejadian tersayat yang menunjukkan hubungan yang signifikan adalah alat yang di gunakan, untuk itu disarankan kepada Disperindagkop untuk meningkatkan pembinaan kepada pekerja serta pekerja diharapkan berkonsentrasi, fokus serta menggunakan APD saat melakukan pekerjaannya.
\end{abstract}

Kata Kunci : Kecelakaan Kerja, Kejadian Tersayat, Pembersih Bawang

\begin{abstract}
Workplace accidents are unexpected events that occur when the workers doing work. The accidents can arise from several factors; those are human factors, environmental factors and equipment factors. This research aimed to know the relationship of the caused factors between workplace accidents and the incidence of slicing on onion cleaners at Segiri and Kedondong Markets, Samarinda. This study belongs to explanatory research and used a cross-sectional design with the total sample of 31 respondents. The variables were the tools usage, lighting, working period, age and the PPE usage. The result of the chi square test analysis showed that there was a relationship between the tools usage $(p=0.006)$, lighting $(p=0.038)$, working period $(p=0.013)$, age $(p=0.045)$, and the PPE usage $(p=0.017)$ with the incidents of slicing on onion cleanser. The tools usage was the most significant factor that caused of slicing incidents. Therefore, this study suggests the inspectors to intensify their control of the workers, observes the work environment and the safety of workplace. Likewise to Disperindagkop this study recommends to improve working trainings, and the workers are expected to be more concentrate, focus and use PPE while doing their work.
\end{abstract}

Keywords: Workplace Accidents, Incidents Of Slicing, the Onion Cleaners 


\section{PENDAHULUAN}

\section{A. Latar Belakang}

Setiap manusia dapat bekerja dengan baik dan nyaman apabila pekerjaan dan tempat kerjanya aman dan sehat. Sebaliknya apabila suatu pekerjaan dan tempat kerja tersebut tidak aman dan sehat, maka bisa saja mengakibatkan kecelakaan kerja. Selain tempat kerja dan pekerjaan, faktorfaktor kecelakaan kerja juga sangat banyak antara lain, faktor lingkungan, faktor peralatan atau mesin bahkan faktor manusia itu sendiri.

Menurut ILO, setiap tahunnya lebih dari 250 juta kecelakaan terjadi di tempat kerja dan 160 juta pekerja menderita penyakit akibat bekerja di tempat kerja. Dan lagi 1,2 juta pekerja meninggal akibat kecelakaan dan sakit di tempat kerja (ILO, 2013).

Direktur Pelayanan Badan Penyelenggara Jaminan Sosial (BPJS) Ketenagakerjaan Khrisna Syarif, di Indonesia terjadi peningkatan kecelakaan kerja sekitar 20\% dibandingkan tahun 2016. Total kecelakaan kerja pada 2017 sebanyak 123 ribu kasus dengan nilai klaim 971 miliar. Angka ini meningkat dari tahun 2016 dengan nilai klaim hanya 792 miliar lebih (Saut, 2018). Kemudian Angka kecelakaan kerja kaltim terus meningkat setiap tahun. Berdasarkan data Jamsostek Samarinda, pada tahun 2012 terdapat 398 kasus kecelakaan kerja di Samarinda, angka tersebut meningkat pada September 2013 hingga 498 kasus (Dwinanto, 2013).

Sedangkan pada sektor informal, menurut BPJS Ketenagakerjaan, hingga di akhir tahun 2015 telah terjadi kecelakaan kerja sebanyak 105.182 kasus dengan jumlah kasus kematian berada pada angka 2.375 kasus. Kondisi ini semakin menunjukan urgensi bagi pemerintahan khususnya untuk melindungi angkatan kerja di sektorsektor informal (Muthahhari, 2017).

Berdasarkan observasi yang dilakukan oleh peneliti pada pekerja pembersih bawang di pasar Segiri dan Kedondong terdapat 31 pekerja pembersih bawang yang ada di pasar Segiri dan Kedondong kota Samarinda. Pada 15 orang pekerja pembersih bawang di kedua pasar tersebut, peneliti mengambil 10 sampel di Pasar Segiri dan 5 sampel di pasar kedondong dengan jumlah 6 kejadian tersayat dari 10 responden di Pasar Segiri dan 3 kejadian tersayat dari 5 responden di Pasar Kedondong. Pekerja pembersih bawang menggunakan Cutter dan gunting sebagai alat untuk membersihkan bawang. Selain itu kondisi pencahayaan di beberapa kios sangat minim dan beberapa pekerja juga ada yang tidak memakai APD.

\section{B. Rumusan Masalah}

Bagaimana Faktor Penyebab Kecelakaan Kerja dengan Kejadian Tersayat pada Pekerja Pembersih Bawang di Pasar Segiri dan Pasar Kedondong Samarinda Tahun 2018 ?

\section{Metode Penelitian}

Jenis penelitian ini adalah explanatory research dan menggunakan desain cross-sectional (potong lintang) dengan total sampel sebanyak 31 responden. Penelitian ini dilakukan pada bulan Juli-Agustus dan bertempat di Pasar Segiri dan Pasar Kedondong Samarinda.

\section{HASIL DAN PEMBAHASAN}

Berikut adalah tabel untuk distribusi frekuensi responden yaitu usia, masa kerja, pencahayaan, penggunaan APD dan alat yang digunakan : 
Tabel 1. Distribusi Frekuensi Responden

Karakteristik Frekuensi Persentase

(\%)

\section{Usia}

$<45$ tahun
$\geq 45$ tahun
Total
Masa Kerja
$<3$ tahun

$\geq 3$ tahun

Total

Pencahayaan

Standar

Tidak Standar

Total

Penggunaan

APD

Menggunakan

APD

Tidak

menggunakan

APD

Total

Alat

digunakan

Cutter

Gunting

Total

Kejadian

Tersayat

\begin{tabular}{lcc} 
Tidak & 16 & $52 \%$ \\
Ya & 15 & $48 \%$ \\
\hline Total & 31 & $100 \%$ \\
\hline \multicolumn{1}{r}{ Berdasarkan } & tabel & di atas,
\end{tabular}

sebagaian besar pekerja yang mengalami kejadian tersayat adalah pekerja dengan usia $\geq 45$ tahun (55\%). Pekerja yang mengalami kejadian tersayat sebagain besar pekerja dengan masa kerja $\geq 3$ tahun $56 \%$. Pekerja yang mengalami kejadian tersayat memiliki tingkat pencahayaan yang rendah pada tempat kerjanya sebanyak 19 tempat kerja $61 \%$.
Pekerja yang mengalami kejadian tersayat sebagaian besar adalah pekerja yang menggunakan gunting sebanyak 11 orang (35\%) dan pekerja yang mengalami kejadian tersayat sebagaian besar juga tidak menggunakan APD (Alat Pelindung Diri) sebanyak 18 orang (58\%), dengan total kejadian tersayat pada semua variabel sebesar 15 kejadian dengan persentase sebesar $48 \%$.

Tabel 2. Tabel Silang antara Alat yang digunakan dengan Kejadian Tersayat

\begin{tabular}{|c|c|c|c|c|}
\hline \multirow{3}{*}{$\begin{array}{c}\text { Alat } \\
\text { yang } \\
\text { Digunak } \\
\text { an }\end{array}$} & $\begin{array}{l}\text { Keja } \\
\text { Ters }\end{array}$ & $\begin{array}{l}\text { dian } \\
\text { ayat }\end{array}$ & & \multirow{2}{*}{$\begin{array}{c}p \\
\text { valu } \\
e\end{array}$} \\
\hline & $\begin{array}{c}\text { Tidak } \\
(+)\end{array}$ & Ya (-) & Jumlah & \\
\hline & $\mathrm{N} \quad \%$ & $\%$ & $\%$ & \\
\hline
\end{tabular}

$\begin{array}{lllllll}\text { Cutter } & 1 & 4 & 6 & 1 & 2 & 65 \\ & 4 & 5 & 6 & 9 & 0 & 65\end{array}$

$\begin{array}{lllllll}\text { Gunting } & 2 & 6 & 9 & 2 & 1 & 9\end{array}$

\begin{tabular}{ccccccc}
\multirow{2}{*}{ Jumlah } & 1 & 5 & 1 & 4 & 3 & 10 \\
& 6 & 2 & 5 & 8 & 1 & 0 \\
\hline
\end{tabular}

Berdasarkan tabel 2 dapat dilihat terdapat hubungan antara alat yang digunakan dengan kejadian tersayat pada pembersih bawang di pasar Segiri dan pasar Kedondong Samarinda dengan nilai $\mathrm{p}$-value $=0,006$. Hal ini sesuai dengan penelitian Handayani (2010), dalam penelitiannya tentang Penggunaan Alat Pelindung Diri, Umur dan Masa Kerja dengan Kecelakaan Kerja pada Pekerja bagian Rustic di PT Borneo Melintang Buana Eksport menyebutkan bahwa pekerja bagian Rustic yang mengalami kecelakaan teriris atau tersayat benda tajam 
merupakan kelompok kecelakaan yang tertinggi yaitu sebanyak $81,08 \%$.

Dalam penelitian ini paling banyak mengalami kejadian tersayat dengan menggunakan gunting daripada cutter, karena pekerja yang menggunakan cutter bekerja dengan lebih fokus, ada pengawasan langsung dari atasan serta mengejar target pendapatan. Dimana dalam pekerjaan ini semakin banyak bawang yang di bersihkan, semakin banyak pula upah yang akan di dapatkan oleh para pekerja. Hal ini di buktikan dengan jumlah pekerja pengguna cutter sebanyak 14 orang responden tidak mengalami kejadian tersayat. Sedangkan pada pekerja pembersih bawang yang menggunakan gunting, mereka bekerja secara berkelompok dan sedikit lebih santai, sehingga pekerja membersihkan bawang sambil bergurau dengan kelompoknya. Ini dibuktikan dengan hasil penelitian terhadap jumlah responden pekerja pengguna gunting yang tidak megalami kejadian tersayat sebanyak 2 orang responden sedangkan yang mengalami kejadian tersayat sebanyak 9 responden dari 11 pekerja yang menggunakan gunting. Hal ini merupakan salah satu perilaku tidak aman membahayakan biasa disebut dengan Unsafe Action.

Unsafe Action adalah tindakan tidak aman yang berkaitan erat dengan faktor manusia berupa budaya $\mathrm{k} 3$ atau tindakan yang dilakukan pekerja dimana tindakan tersebut dapat membahayakan diri sendiri, orang lain, peralatan serta lingkungan sekitarnya (Anshari, 2017).

Sedangkan salah satu faktor lain penyebab responden pengguna gunting lebih banyak mengalami kejadian tersayat karena tidak adanya pengawasan dari atasan sehingga responden bekerja secara santai dan tidak ada peraturan yang mengikat. Hal ini juga di dukung dengan penelitian
Anshari (2017), yang menyatakan bahwa ada hubungan yang bermakna antara pengawasan dengan kecelakaan kerja.

Tabel 3. Tabel silang antara pencahayaan dengan Kejadian Tersayat

\begin{tabular}{|c|c|c|c|c|c|c|c|}
\hline \multirow{3}{*}{$\begin{array}{c}\text { Pencahay } \\
\text { aan }\end{array}$} & \multicolumn{4}{|c|}{$\begin{array}{l}\text { Kejadian } \\
\text { Tersayat }\end{array}$} & \multirow{2}{*}{\multicolumn{2}{|c|}{ Jumlah }} & \multirow{3}{*}{$\begin{array}{c}p \\
\text { valu } \\
e\end{array}$} \\
\hline & \multicolumn{2}{|c|}{$\begin{array}{l}\text { Tidak } \\
(+)\end{array}$} & \multicolumn{2}{|c|}{ Ya (-) } & & & \\
\hline & $\mathrm{N}$ & $\%$ & $\mathrm{~N}$ & $\%$ & $\mathrm{~N}$ & $\%$ & \\
\hline Standar & 9 & $\begin{array}{l}2 \\
9\end{array}$ & 3 & $\begin{array}{l}1 \\
0\end{array}$ & $\begin{array}{l}1 \\
2\end{array}$ & 39 & \\
\hline $\begin{array}{l}\text { Tidak } \\
\text { Standar }\end{array}$ & 7 & $\begin{array}{l}2 \\
3\end{array}$ & $\begin{array}{l}1 \\
2\end{array}$ & $\begin{array}{l}3 \\
9\end{array}$ & $\begin{array}{l}1 \\
9\end{array}$ & 61 & $\begin{array}{c}0,03 \\
8\end{array}$ \\
\hline Jumlah & $\begin{array}{l}1 \\
6\end{array}$ & $\begin{array}{l}5 \\
2\end{array}$ & $\begin{array}{l}1 \\
5\end{array}$ & $\begin{array}{l}4 \\
8\end{array}$ & $\begin{array}{l}3 \\
1\end{array}$ & $\begin{array}{c}10 \\
0\end{array}$ & \\
\hline
\end{tabular}

Sumber : Data Primer, 2018

Pada pekerja pembersih bawang di Pasar Segiri dan Pasar Kedondong Samarinda, standar pencahayaan yang di pakai adalah Permenkes No.70 Tahun 2016 pada bagian Standar Pencahayaan Industri Kerajinan Pangan tentang pemotongan dan pemilahan buahbuahan dan sayur-sayuran sebesar 300 lux. Berdasarkan tabel 3 dapat dilihat terdapat hubungan anatara pencahayaan dengan kejadian tersayat dengan nilai Pvalue sebesar 0,038 yang artinya 0,038 $<0,05$ yang menandakan ada hubungan yang signifikan antara pencahayaan dengan kejadian tersayat. Jika responden tidak mendapatkan cahaya yang optimal secara terus-menerus maka tidak menutup kemungkinan akan terjadinya kelelahan pada mata. Kelelahan mata sangat berpengaruh terhadap penurunan kinerja pekerja. Karena kelelahan mata bukan tidak mungkin dapat menyebabkan 
kecelakaan kerja. Salah satu faktor penyebab kelelahan mata adalah intensitas cahaya (Sawitri, 2017).

Hal ini sesuai dengan penelitian Sawitri (2017) yang menyimpulkan adanya hubungan intensitas pencahayaan dengan kelelahan mata berdasarkan hasil uji Chi Square dengan $\mathrm{p}=0,001$ di peroleh nilai $\mathrm{P}$-value $<0,05$ yang berarti ada hubungan antara intensitas pencahayaan dengan kelelahan mata.

Tabel 4. Tabel silang antara masa kerja dengan Kejadian Tersayat

\begin{tabular}{|c|c|c|c|c|c|c|c|}
\hline \multirow{3}{*}{$\begin{array}{l}\text { Masa } \\
\text { Kerja }\end{array}$} & \multicolumn{4}{|c|}{$\begin{array}{l}\text { Kejadian } \\
\text { Tersayat }\end{array}$} & \multirow{2}{*}{\multicolumn{2}{|c|}{ Jumlah }} & \\
\hline & & dak & & & & & value \\
\hline & $\mathrm{N}$ & $\%$ & $\mathrm{~N}$ & $\%$ & $\mathrm{~N}$ & $\%$ & \\
\hline
\end{tabular}

$\begin{array}{llllllll}<3 & 9 & 29 & 2 & 6 & 11 & 35 & \\ \begin{array}{l}\text { tahun } \\ \end{array} & & & & & & & \\ \geq 3 & 7 & 23 & 13 & 42 & 20 & 65 & \\ \begin{array}{l}\text { tahun } \\ \text { ahu }\end{array} & & & & & & & \end{array}$

\begin{tabular}{lllllll}
\hline Jumlah & 16 & 52 & 15 & 48 & 31 & 100
\end{tabular}

Sumber : Data Primer, 2018

Berdasarkan penelitian ditemukan ada hubungan yang cukup signifikan antara masa kerja dengan kejadian tersayat pada pembersih bawang di pasar segiri dan pasar kedondong Samarinda, dengan nilai $\mathrm{P}$ value sebesar 0,013 . Hal ini sejalan dengan penelitian penelitian Pangestuti (2015) tentang hubungan shift kerja dan masa kerja dengan kejadian kecelakaan kerja di PT. $\mathrm{X}$ Sragen diperoleh nilai $\mathrm{p}=0,035<$ 0,05 maka ada hubungan yang signifikan antara masa kerja dengan kejadian kecelakaan kerja. Masa kerja masuk ke dalam faktor yang mempengaruhi kelelahan kerja karena kelelahan yang terjadi karena lamanya bekerja akan mempengaruhi mekanisme di dalam tubuh manusia seperti pencernaan, peredaran darah, otot syaraf serta pernafasan (Sedarmayanti, 1996 dalam Atiqoh, 2014). Jika pekerja terusmenerus mengalami kelelahan, selain menyebabkan menurunnya produktivitas kerja maka akan meningkatkan resiko terjadinya kecelakaan kerja.

Tabel 5. Tabel silang antara Usia dengan Kejadian Tersayat

\begin{tabular}{|c|c|c|c|c|c|c|c|}
\hline \multirow{3}{*}{ Usia } & \multicolumn{4}{|c|}{$\begin{array}{l}\text { Kejadian } \\
\text { Tersayat }\end{array}$} & \multirow{2}{*}{\multicolumn{2}{|c|}{ Jumlah }} & \multirow{3}{*}{$\begin{array}{c}P \\
\text { Value }\end{array}$} \\
\hline & \multicolumn{2}{|c|}{$\begin{array}{l}\text { Tidak } \\
(+)\end{array}$} & \multicolumn{2}{|c|}{ Ya (-) } & & & \\
\hline & $\mathrm{N}$ & $\%$ & $\mathrm{~N}$ & $\%$ & $\mathrm{~N}$ & $\%$ & \\
\hline $\begin{array}{l}<45 \\
\text { Tahun }\end{array}$ & 10 & 32 & 4 & 13 & 14 & 45 & \\
\hline $\begin{array}{l}\geq 45 \\
\text { tahun }\end{array}$ & 6 & 19 & 11 & 35 & 17 & 55 & $0,04 J$ \\
\hline Jumlah & 16 & 52 & 15 & 48 & 31 & 100 & \\
\hline
\end{tabular}

Sumber : Data Primer, 2018

Hasil penelitian pada pekerja pembersih bawang di pasar Segiri dan pasar Kedondong Samarinda menunjukkan adanya hubungan yang signifikan antara masa kerja dengan kejadian tersayat dengan nilai $\mathrm{P}$-value 0,013 dimana $0,013<0,05$ yang berarti ada hubungan masa kerja dengan kejadian tersayat. Masa kerja dapat menentukan tingkat kecelakaan kerja karena masa kerja lama atau semakin lama masa kerja seseorang maka seseorang atau pekerja tersebut akan lebih berpengalaman dalam melakukan pekerjaan dibandingkan dengan pekerja yang baru bekerja (Pinggian, 2016).

Pada usia $\geq 45$ tahun merupakan masa dimana terjadinya proses degerasi atau penurunan fungsi organ, sehingga fungsi organ akan menurun seiring bertambahnya usia responden dalam 
bekerja, hal ini sejalan dengan penelitian Atiqoh (2014) yang menyebutkan bahwa ada hubungan antara usia dengan kelelahan kerja, dimana saat responden berusia $>40$ tahun maka kapasitas kerja seseorang berkurang menjadi 80\%-60\% dibandingkan dengan kapasitas kerja responden yang berusia 25 tahun. Saat memasuki usia 40 tahun, pekerja akan cenderung mengalami kelelahan kerja berat karena pada saat usia bertambah maka akan terjadi proses degenerasi dari fungsi organ, sehingga fungsi organ akan menurun.

Semakin bertambahnya umur seseorang maka tingkat kelelahan akan semakin tinggi hal ini tentu saja beresiko menyebabkan terjadinya kecelakaan kerja. Usia juga akan mempengaruhi kondisi, kemampuan dan kapasitas tubuh dalam melakukan aktivitas. Kelelahan berat yang di alami oleh responden $\geq 40$ tahun disebabkan karena kondisi fisik mengalami penurunan sehingga berpotensi mengalami kecelakaan kerja (Tarwaka, 2014 dalam Frely, 2017).

\begin{tabular}{|c|c|c|c|c|c|c|c|}
\hline Tabel & $\begin{array}{l}\mathbf{6 .} \\
\text { Peng } \\
\text { Keja }\end{array}$ & $\begin{array}{l}\text { Tal } \\
\text { una } \\
\text { ian }\end{array}$ & $\begin{array}{l}\text { an } \\
\text { Ter }\end{array}$ & $\begin{array}{r}\mathrm{A} \\
\text { ayy }\end{array}$ & & & \\
\hline \multirow[t]{2}{*}{$\begin{array}{l}\text { Penggunaan } \\
\text { APD }\end{array}$} & \multicolumn{2}{|c|}{$\begin{array}{l}\text { Kejadian } \\
\text { Tersayat } \\
\text { Tidak } \\
(+)\end{array}$} & \multicolumn{2}{|c|}{ Ya (-) } & \multicolumn{2}{|c|}{ Jumlah } & $\begin{array}{l}P \\
\text { Value }\end{array}$ \\
\hline & $\mathrm{N}$ & $\%$ & $\mathrm{~N}$ & $\%$ & $\mathrm{~N}$ & $\%$ & \\
\hline $\begin{array}{l}\text { Menggunakan } \\
\text { APD }\end{array}$ & 10 & 32 & 3 & 10 & 13 & 42 & \\
\hline $\begin{array}{l}\text { Tidak } \\
\text { Menggunakan } \\
\text { APD }\end{array}$ & 6 & 19 & 12 & 39 & 18 & 58 & \\
\hline Jumlah & 16 & 52 & 15 & 48 & 31 & 10 & \\
\hline
\end{tabular}

Sumber : Data Primer, 2018

Berdasarkan hasil penelitian dapat dilihat bahwa hubungan penggunaan
APD dengan kejadian tersayat terdapat hubungan yang signifikan dengan nilai P-value $0,017<0,05$. Hal ini sesuai dengan Repi dkk (2016) bahwa ada hubungan antara responden yang tidak menggunakan APD dengan kecelakaan kerja, dengan persentase responden yang tidak menggunakan APD sebanyak $68,1 \%$. Penelitian ini juga di dukung oleh Handayani (2010) yang menyatakan di dalam penelitiannya terdapat hubungan antara penggunaan APD dengan kecelakaan kerja pada pekerja bagian rustic di PT. Borneo Melintang Buana Eksport yogyakarta.

Berdasarkan hasil penelitian juga telah di temukan ada 3 responden pekerja $(10 \%)$ yang mengalami kecelakaan kerja saat menggunakan APD. Berdasarkan observasi ditemukan bahwa pekerja yang menggunakan APD tetapi masih mengalami kecelakaan kerja ini disebabkan oleh penggunaan APD hanya di lakukan setelah mengalami kejadian tersayat. Jadi pekerja awalnya tidak memakai APD kemudian setelah mengalami kejadian tersayat pekerja memakai APD untuk menutupi luka.

Responden merasa tidak nyaman saat menggunakan APD selain itu kurangnya pengetahuan terhadap fungsi APD juga masih kurang. Hal ini juga diungkapkan oleh Helda (2007) yang menyatakan bahwa pengetahuan mempengaruhi cara berfikir pekerja saat menghadapi pekerjaan termasuk cara pekerja tersebut mencegah dan menghindari kecelakaan saat melakukan pekerjaannya (Pertiwi, 2016). Pengetahuan seseorang juga akan membuat seseorang mudah dalam pengambilan keputusan dan tidak raguragu dalam bekerja, kondisi ini tentu saja dapat mengurangi resiko kejadian kecelakaan kerja.

\section{SIMPULAN}


1. Ada hubungan yang signifikan antara alat yang digunakan dengan kejadian tersayat pada pembersih bawang di pasar Segiri dan pasar Kedondong Samarinda dengan nilai P-value 0,006 $<0,05$.

2. Terdapat hubungan antara pencahayaan dengan kejadian tersayat dengan nilai P-Value 0,038 dengan intensitas pencahayaan yang memenuhi standar (300 lux) sebesar $39 \%$ dan yang tidak memenuhi standar sebesar $61 \%$.

3. Ada hubungan antara masa kerja dengan kejadian tersayat pada pembersih bawang di pasar Segiri dan pasar Kedondong Samarinda dengan nilai $\mathrm{P}$-value $0,013<0,05$ dengan persentase pekerja paling banyak bekerja dengan masa kerja $\geq$ 3 tahun sebanyak $65 \%$.

4. Terdapat hubungan antara usia dengan kejadian tersayat pada pekerja pembersih bawang dengan kejadian tersayat pada pekerja pembersih bawang di pasar Segiri dan Pasar Kedondong Samarinda dengan nilai $\mathrm{P}$-value 0,045 dengan usia paling banyak $\geq 45$ tahun dengan persentase $55 \%$.

5. Terdapat hubungan antara penggunaan APD dengan kejadian tersayat pada pekerja pembersih bawang di pasar segiri dan Pasar Kedondong Samarinda dengan nilai P-value 0,017 dengan persentase pekerja yang tidak menggunakan APD sebesar $61 \%$.

\section{DAFTAR PUSTAKA \\ Buku/Literatur:}

Anshari, L. H. (2017). Faktor-faktor yang Berhubungan Dengan Kecelakaan Kerja Pada Karyawan PT. Kunanggo Jantan Kota Padang . IKAKESMADA "Peran Tenaga Kesehatan dalam Pelaksanaan SDG's". Repository Universitas Ahmad Dahlan

Atiqoh, J. (2014, Februari). Faktorfaktor yang Berhubungan dengan Kelelahan Kerja pada Pekrja Konveksi Bagian Penjahitan di CV Aneka Garmen Gunungpati Semarang. Jurnal Kesehatan Masyarakat, Vol.2.

Dwinanto, R. A. (2013, Oktober 24). Tribun Kaltim: http://www.tribunnews.com/regi onal/2013/10/24/kecelakaankerja-di-samarinda-capai-498kasus. Diakses 22 Mei 2018

Frely, A. N. (2017). Hubungan antara UmurMasa Kerja dan Lama Kerja dengan Kelelahan Kerja pada Pengemudi Truk Tangki di Terminal Bahan Bakar Minyak (BBM) PT Pertamina Bitung. Media Kesehatan, Vol 9.

Handayani, E. (2010). Penggunaan Alat Pelindung Diri, Umur dan Masa Kerja dengan Kecelakaan Kerja pada Pekerja bagian Rustic di PT Borneo Melintang Buana Eksport . Kes Mas.

International Labour Organization (ILO). (2013). Keselamatan dan Kesehatan Kerja Sarana untuk Produktivitas. Jakarta.

Muthahhari, T. (2017, Oktober 24). Nasib Malang Para Pekerja Sektor Informal. Tirto.id: https://tirto.id/nasib-malangpara-pekerja-sektor-informal. Diakses 15 Juli 2018.

Pangestuti, G. (2015). Hubungan Shift Kerja dan Masa Kerja dengan Kejadian Kecelakaan Kerja di PT. $X \quad$ Sragen. UPT Perpustakaan Sebelas Maret: digilib.uns.ac.id. Diakses 14 Agustus 2018

Pertiwi, P. (2016). Hubungan Antara Perilaku Keselamtan dan 
Kesehatan Kerja (K3) dengan Kejadian Kecelakaan Kerja Pada Pekerja di PT Aneka Andhilogam Karya Ceper, Klaten 2016. Jurnal UMS

Pinggian, D. (2016). Faktor-faktor yang Berhubungan dengan Kecelakaan Kerja pada Buruh Angkut Sampah di Kota Manado. Community Health, Vol.1.

Repi, dkk. (2016). Hubungan Antara Pengetahuan dan Sikiap dengan Tindakan Penggunaan Alat Pelindung Diri pada Tenaga Kerja di PT Tropica Cocoprima Desa Lelema Kecamatan
Tumpaan Kabupaten minahasa Selatan. KESMAS, Vol.5

Saut, P. D. (2018, Februari 6). Detik Finance. Detik.com: https://finance.detik.com/monete r/d-3853101/angka-kecelakaankerja-ri-meningkat-ke-123-ribukasus-di-2017. Diakses 22 Mei 2018.

Sawitri, M. A. (2017). Hubungan Antara Intensitas Pencahyaan dan Usia dengan Kelelahan Mata pada Pekerja di Bagian Operasional PT.Angkasa Pura I (Persero) Kota Manado Tahun 2017. FKM Unsrat. 